\title{
Characterization of Carbon Nanotube/Graphene on Carbon Cloth as an Electrode for Air-Cathode Microbial Fuel Cells
}

\author{
Hung-Yin Tsai, ${ }^{1}$ Wei-Hsuan Hsu, ${ }^{2}$ and Ying-Chen Huang ${ }^{1}$ \\ ${ }^{1}$ Department of Power Mechanical Engineering, National Tsing Hua University, Hsinchu 30013, Taiwan \\ ${ }^{2}$ Department of Mechanical Engineering, National United University, Miaoli 36003, Taiwan
}

Correspondence should be addressed to Hung-Yin Tsai; hytsai@pme.nthu.edu.tw

Received 29 August 2014; Revised 26 November 2014; Accepted 24 December 2014

Academic Editor: Jin H. Kim

Copyright (c) 2015 Hung-Yin Tsai et al. This is an open access article distributed under the Creative Commons Attribution License, which permits unrestricted use, distribution, and reproduction in any medium, provided the original work is properly cited.

\begin{abstract}
Microbial fuel cells (MFCs), which can generate low-pollution power through microbial decomposition, have become a potentially important technology with applications in environmental protection and energy recovery. The electrode materials used in MFCs are crucial determinants of their capacity to generate electricity. In this study, we investigate the performance of using carbon nanotube (CNT) and graphene-modified carbon-cloth electrodes in a single-chamber MFC. We develop a process for fabricating carbon-based modified electrodes and Escherichia coli HB101 in an air-cathode MFC. The results show that the power density of MFCs can be improved by applying a coat of either graphene or CNT to a carbon-cloth electrode, and the graphene-modified electrode exhibits superior performance. In addition, the enhanced performance of anodic modification by CNT or graphene was greater than that of cathodic modification. The internal resistance decreased from $377 \mathrm{k} \Omega$ for normal electrodes to $5.6 \mathrm{k} \Omega$ for both electrodes modified by graphene with a cathodic catalyst. Using the modified electrodes in air-cathode MFCs can enhance the performance of power generation and reduce the associated costs.
\end{abstract}

\section{Introduction}

In the last decade, due to the lack of energy and the rise of environmental awareness, scientists and researchers have been looking for some more alternative energies with renewability and low pollution. Microbial fuel cells (MFCs) are an excellent potential technology that converts the energy, released by breaking chemical bonds of organic compounds, into electrical energy through catalytic reactions of microorganisms under anaerobic conditions. The concept of using microorganisms as catalysts in fuel cells was explored in the 1910s [1, 2]. At that time, fuel cell technology was neither mature nor taken seriously since Potter's MFC could merely produce weak power. Until the energy crisis and the breakthrough in fuel cell technology, the performance of MFC is improved gradually and taken seriously.

A typical MFC system consists of two chambers, anode and cathode, separated by proton exchange membrane (PEM). MFC can convert chemical energy directly into electrical one by the way that the microorganisms oxidize the substrate to produce electrons $\left(\mathrm{e}^{-}\right)$and protons $\left(\mathrm{H}^{+}\right)$in the anode chamber. Electrons, collected on the anode, are transported to cathode by external circuit while protons are transferred internally to the cathode chamber through the membrane. Then electrons and protons reacted with oxygen and form water. According to the anodic oxidation and cathodic reduction, this promoted the electrons in the anode and the cathode to move and generate the battery current [3-7]. In order to obtain higher current, the microbes must effectively decompose organisms so that electrons can be transferred easily. The microorganisms attached on the anode surface allow electrons to transfer smoothly to the anode. To better bacteria attachment on the anode, many studies utilized the porous carbon materials as anodic ones, such as carbon mesh, carbon paper, carbon cloth, and graphite brush [8-15].

In the year 2004, Liu et al. investigated the performance of single-chamber MFC in wastewater treatment [16]. The structure consists of both cathode and anode electrodes placed in a single reaction chamber with PEM directly fused 
to the surface of the cathode. Later in the same year, Liu and Logan further studied the performances of air-cathode single-chamber MFC in the presence and in the absence of PEM, respectively; their study demonstrated the possibility of using MFC systems without the cost of PEM materials [17]. Furthermore, the air-cathode design allows oxygen to pass through the cathode directly and thus reduces the cost to establish air exposure equipments. This design of singlechamber MFC has several advantages over the traditional double-chamber MFCs.

The performance of a MFC is affected by several factors including the microbial inoculation, electrode materials, ionic concentration, catalyst, internal resistance, and electrode spacing [18-21]. The electrode materials play an important role in the electricity generation. To improve the power generation of MFC, many researchers have focused on material modification and upgrade microbe's inoculation.

Carbon nanotubes (CNTs) have many excellent properties such as nanometer size, good electronic conductivity, high surface area, and excellent structure and stability. Some studies show that CNT can enhance microbial fuel cell performance [22, 23]. Recently, researchers and scientists were much interested in graphene, whose existence had been objectively verified with abundant potential applications. Graphene is the world's thinnest and most rigid nanomaterial and has excellent electronic transition [24]. These unique characteristics (high surface area, low resistance, desirable mechanical strength, transparency, etc.) can be compatibly put in use for various fields such as solar cell [25, 26], touchscreens, and supercapacitors [27].

In this study, a set of mediatorless single-chamber MFCs were designed to examine the performance which resulted from different carbon cloth electrodes on which CNTs or graphenes were coated to form a highly conductive electrode with a high specific surface area. In order to evaluate the property and the performance of CNT/graphene modified MFCs, the power density and the internal resistance are compared for different electrodes with or without the presence of $\mathrm{Pt}$ catalyst or modified anodes.

\section{Materials and Methods}

2.1. Preparation of Electrodes. Commercial MWCNTs (Multiwalled Carbon Nanotubes) or graphenes of $20 \mathrm{mg}$ were added to $95 \%$ ethanol of $10 \mathrm{~mL}$, which was sonicated to disperse the CNTs/graphenes for one hour. This resulted in a stable and uniformly dispersed slurry of MWCNTs or graphenes. A carbon cloth was soaked into the MWCNT/graphene solution for one hour, removed, and then baked at $150^{\circ} \mathrm{C}$ for one hour to eliminate residual water. This resulted in a thick, black coating of MWCNTs/graphene on the carbon cloth's surface.

For all experiments, the base material of anode was nonwet proofed carbon cloth (W0S1002, CeTech Co., Ltd, Taiwan) while that of cathode was wet proofed carbon cloth (W1S1005, CeTech Co., Ltd, Taiwan). Some of the cathode carbon cloth contained a platinum catalyst $\left(0.5 \mathrm{mg} \mathrm{cm}^{-2}\right.$, $20 \mathrm{wt} \% \mathrm{Pt})$.

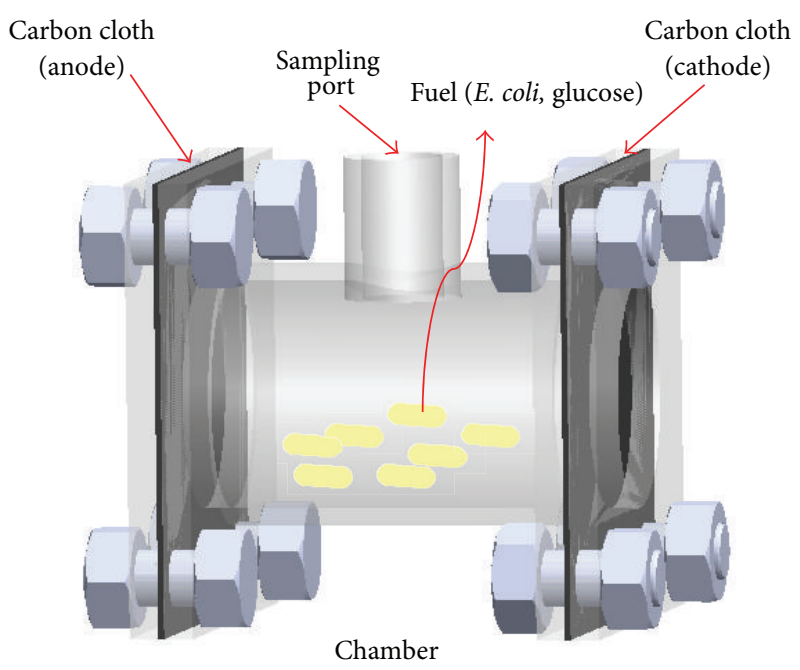

FIGURE 1: The schematic of air-cathode MFC used in the current study. The PMMA chamber was designed as the air-cathode singlechamber MFC. Use different types of carbon cloth (modified or unmodified) as electrode and connect them with external resistance with copper wires. Use glucose as fuel and Escherichia coli as anode's catalyst.

TABLE 1: Electrode conditions of the MFCs in the current study.

\begin{tabular}{lcc}
\hline \multirow{2}{*}{ Experimental cases } & \multicolumn{2}{c}{ Electrode } \\
& Anode & Cathode \\
\hline MFC-NN & Normal & Normal \\
MFC-GN & Graphene & Normal \\
MFC-CN & CNT & Normal \\
MFC-NP & Normal & $\mathrm{Pt}$ \\
MFC-GP & Graphene & $\mathrm{Pt}$ \\
MFC-CP & $\mathrm{CNT}$ & $\mathrm{Pt}$ \\
MFC-NGP & Normal & Graphene $+\mathrm{Pt}$ \\
MFC-GGP & Graphene & Graphene $+\mathrm{Pt}$ \\
MFC-NCP & Normal & $\mathrm{CNT}+\mathrm{Pt}$ \\
MFC-CCP & CNT & $\mathrm{CNT}+\mathrm{Pt}$ \\
\hline
\end{tabular}

2.2. MFC Design. Figure 1 shows the air-cathode MFC used in the current study, which is the same as reported earlier [13]. The single-chamber MFC is fabricated from polymethyl methacrylate (PMMA). The shape of the single-chamber MFC is cylinder, whose diameter, length, and wall thickness are $5 \mathrm{~cm}, 6 \mathrm{~cm}$, and $0.5 \mathrm{~cm}$, respectively. A cathode electrode was fixed to the air-side, and an anode electrode was fixed to the opposite of the chamber. Therefore, reactor volume is approximately $75 \mathrm{~mL}$, and the surface area of cathode and anode is approximately $12.57 \mathrm{~cm}^{2}$. Copper wire was used to connect the circuit $(1000 \Omega$ resistor except when stated otherwise).

In this study, ten different types of single-chamber MFCs were constructed to compare the performances of the MFCs as shown in Table 1. In order to distinguish different types of reactors, we name these groups with notation. The first letter represents the anodic condition; the second and third 

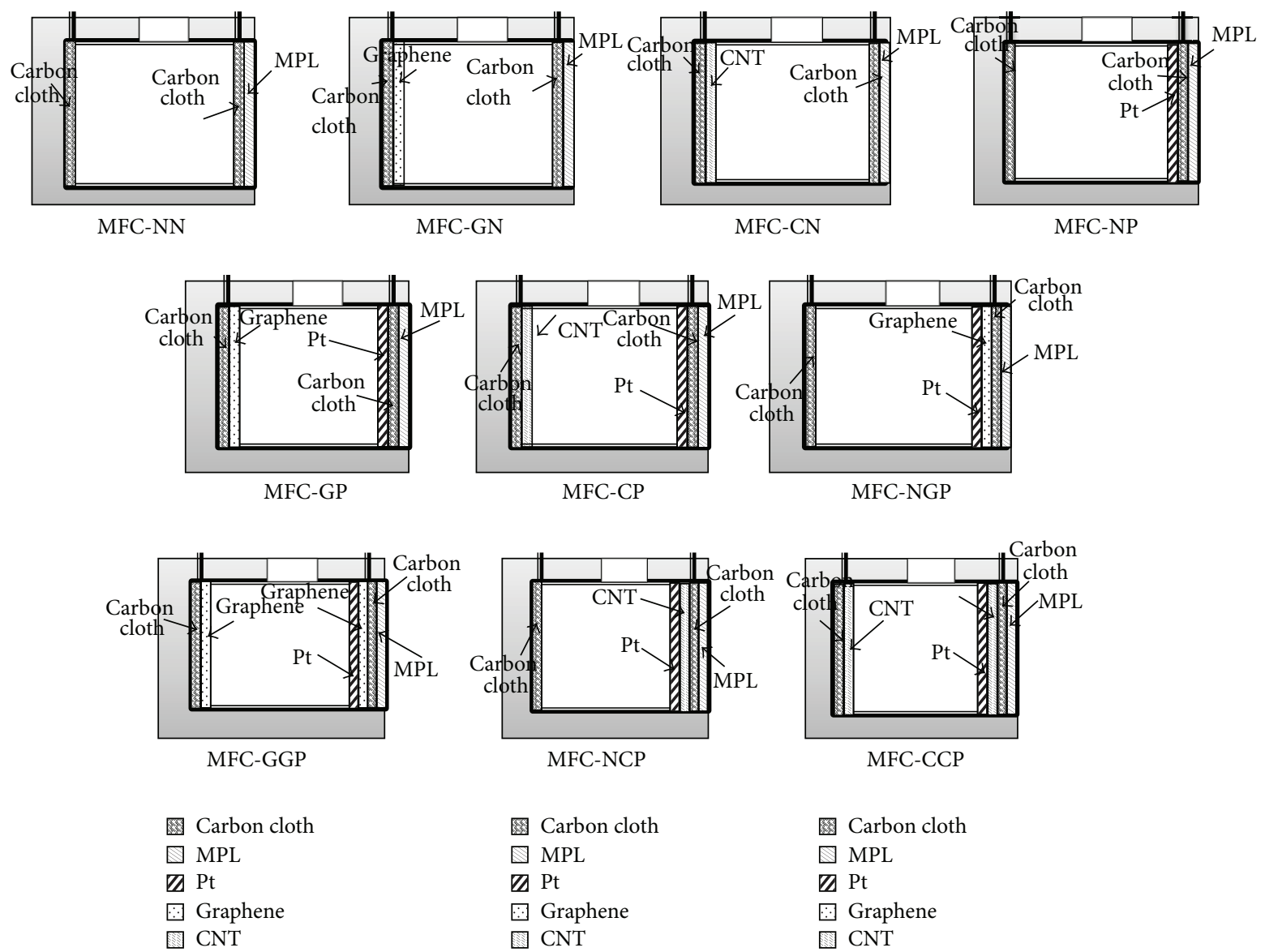

FIGURE 2: Schematic diagrams of electrode conditions for different MFCs.

letters represent the cathodic condition. $\mathrm{N}$ represents the normal carbon cloth; $\mathrm{G}$ represents the carbon cloth modified by graphene; $\mathrm{C}$ represents the carbon cloth modified by CNT; and $\mathrm{P}$ represents the cathode with platinum catalyst. Figure 2 illustrated the structures of different types of MFCs used in the experiment.

\subsection{Microorganisms and Electrode Reactions. Escherichia coli} (E. coli) HB101 was grown anaerobically in the atmosphere of $\mathrm{N}_{2}$ gas for $40 \mathrm{~h}$ to the stationary phase in LB medium $\left(10 \mathrm{gL}^{-1}\right.$ tryptone, $5 \mathrm{gL}^{-1}$ yeast extract, and $\left.10 \mathrm{gL}^{-1} \mathrm{NaCl}\right)$ at $37^{\circ} \mathrm{C}$. The residual cells were obtained at $4^{\circ} \mathrm{C}$ by centrifugation at 5,000 rpm and then dissolved in $\mathrm{M} 9$ medium $\left(6.78 \mathrm{gL}^{-1}\right.$ $\mathrm{Na}_{2} \mathrm{HPO}_{4}, 3 \mathrm{gL}^{-1} \mathrm{KH}_{2} \mathrm{PO}_{4}, 0.5 \mathrm{gL}^{-1} \mathrm{NaCl}, 1 \mathrm{gL}^{-1} \mathrm{NH}_{4} \mathrm{Cl}$, and $4 \mathrm{gL}^{-1} \mathrm{C}_{6} \mathrm{H}_{12} \mathrm{O}_{6}$ ). The chamber was refilled with $E$. coli solution and inoculated for about two weeks to reach a steady state. MFCs were operated in a temperature controlled room at $30^{\circ} \mathrm{C}$.

In this study, the MFC is based on the biocatalysis of Escherichia coli (E. coli HB101) and glucose is used as the fuel for MFC. The reaction equations at the anode and cathode are described as follows.

At the anode,

$$
\mathrm{C}_{6} \mathrm{H}_{12} \mathrm{O}_{6}+6 \mathrm{H}_{2} \mathrm{O} \longrightarrow 6 \mathrm{CO}_{2}+24 \mathrm{H}^{+}+24 \mathrm{e}^{-}
$$

At the cathode,

$$
24 \mathrm{H}^{+}+6 \mathrm{O}_{2}+24 \mathrm{e}^{-} \longrightarrow 12 \mathrm{H}_{2} \mathrm{O}
$$

In the anodic compartment, glucose is oxidized anaerobically by $E$. coli. The glucose loses the electrons and produces hydrogen ions. The electrons can transfer to the cathode via an external circuit and the hydrogen ions can go through the cathode electrode to the air cathode at the same time. After a complete reaction of MFC system, electricity and water can be produced.

2.4. Measurement and Calculations. Cell voltage was recorded using a multimeter and a data acquisition system (CHY48R). Power density $P\left(\mathrm{Wm}^{-2}\right)$ in MFC tests was calculated according to the equation $P=I V / A$, where $I(\mathrm{~A})$ is the current, $V(\mathrm{~V})$ is the voltage, and $A\left(\mathrm{~m}^{2}\right)$ is the projected cross-sectional area of the anode.

In the fuel cell field, the polarization curve is the most commonly used method to evaluate the performance of power generation. The polarization curve is to describe the relationship between the voltage and the current. E. coli, as the microbe for further power generation, was placed in the tank culture for two weeks when the voltage became stable and changed the external resistance. When the voltage output became stable, data started to be recorded to determine 


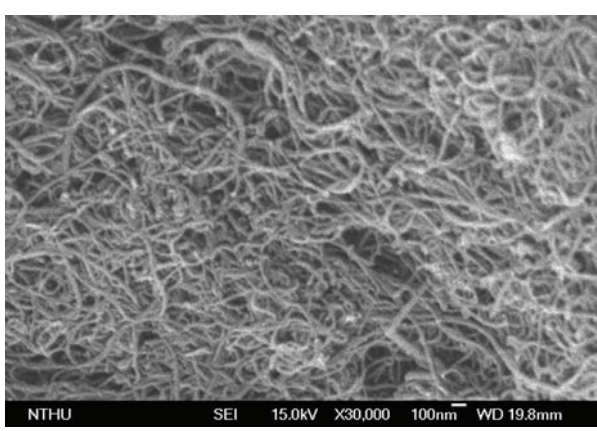

(a)

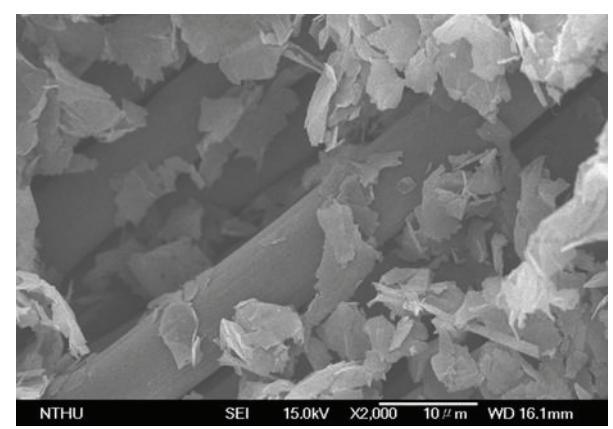

(b)

FIgURE 3: SEM images of carbon nanotube (a) and graphene (b) on the carbon cloth.

the voltage and power generation sustained across a range of current densities obtained by varying the resistance between the electrodes. To obtain the polarization curve and power density curve as a function of current, external circuit resistances were varied from 1 to $20 \mathrm{M} \Omega$. In this study, the polarization slope method was used to calculate the cell's internal resistance. For the Ohm polarization area, the MFCs system has linear relationship between voltage and current. The internal resistance $\left(R_{\mathrm{in}}, \Omega\right)$ within the microbial fuel cell was calculated as

$$
R_{\text {in }}=\frac{\Delta V}{\Delta I},
$$

where $\Delta V$ and $\Delta I$ are the voltage difference $(\mathrm{mV})$ and the current difference $(\mathrm{mA})$ between two points, respectively.

\section{Results and Discussion}

The purpose of these experiments was to assess the difference of the MFC power density with different anode structures composed of CNT, graphene, or none on the associated conditions of the cathode.

3.1. Morphology of CNT and Graphene. Figures 3(a) and 3(b) show the SEM images of MWCNTs and graphene coated on the carbon cloth, respectively. CNTs were curl and divergence-free in the surface of the carbon cloth. Besides, both CNTs and graphene were uniformly distributed on the carbon cloth based on the current treatment methods to approach the original objective for improving the specific surface area of the electrode. According to the specific surface area of graphene and CNT, the active electrochemical area of graphene-coated electrode is about 2 times more than one of CNT-coated electrode.

3.2. Polarization and Power Density. In order to understand the performance effect of the anode with different coating materials, three kinds of anodes with the plain cloth cathodes (the case of MFC-NN, MFC-CN, and MFC-GN) were studied. The power density results of MFCs are shown in Figure 4, in which solid circles represent the power density and hollow circles represent the cell voltage. In addition,

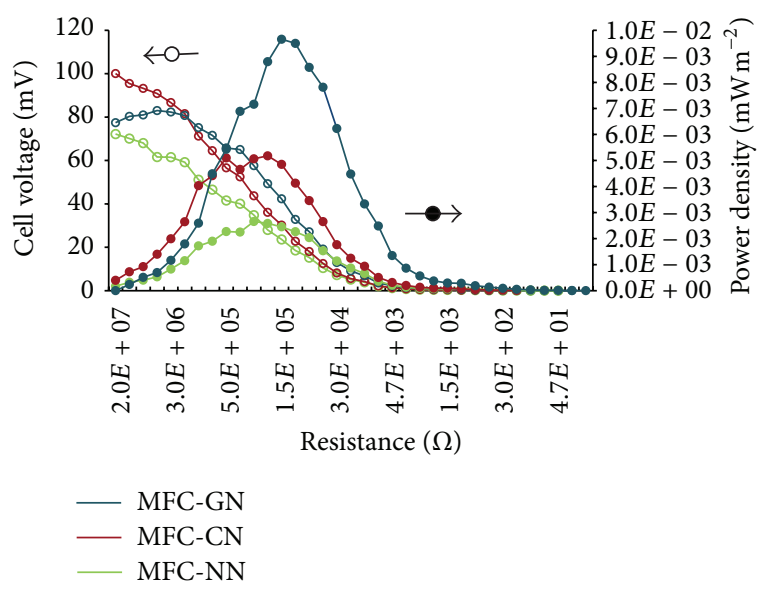

FIGURE 4: Performance diagram for the cases of the anode coated by different materials with the plain cloth cathode only.

the power density of MFC-GN is about 3.5 times more than MFC-NN while MFC-CN is about 1.5 times more than MFC-NN. All the three MFC systems show the same trend that the cell voltage decreases with the decreasing resistance. Typically, a polarization curve can be divided into three regions: activation polarization at high current density, concentration polarization at low current density, and ohmic polarization in the intermediate linear region [28]. The maximum power density of the three cases occurred in ohmic polarization region. In the case of MFC-NN, the maximum power density is $2.66 \mu \mathrm{W} \mathrm{m}^{-2}$. After coating the anodes with CNTs (MFC-CN), the maximum power density is increased to $5.18 \mu \mathrm{W} / \mathrm{m}^{2}$. If CNTs are replaced with a graphene as a coating material, the power density can be further increased to $9.66 \mu \mathrm{W} \mathrm{m}{ }^{-2}$ (MFC-GN). From the results, the power density increases greatly with the decreasing of resistance and has the maximum value of $9.7 \mu \mathrm{W} \mathrm{m}^{-2}$ for the case of the carbon cloth anode coated with graphenes. Coating nanomaterials as graphenes or MWCNTs onto the anode of MFC can increase the surface area and hence improve the electron transfer route.

From Figure 5, MFC-GGP and MFC-NGP with platinum and graphene on the carbon cloth cathode were different in 


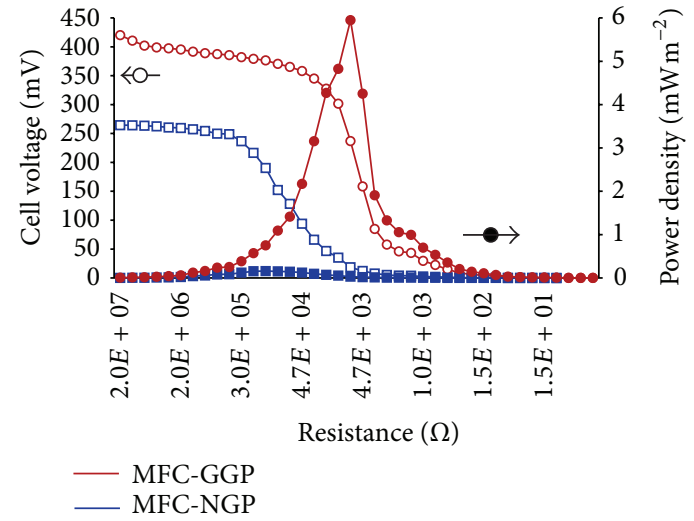

FIGURE 5: Performance diagram for the cases of the anode coated with graphenes or not and with platinum and graphenes coated on the cloth cathode.

the anodic treatment (with graphene or not). The maximum power density of MFC-NGP and MFC-GGP is $159 \mu \mathrm{W} \mathrm{m}{ }^{-2}$ and $5.9 \mathrm{~mW} \mathrm{~m}^{-2}$, respectively, with mutual difference about 37 times. These results showed that adding graphenes on the anode can enhance the power generation. The reason could be that the graphene not only increased the surface area that provided bacteria with more space for adhesion but also enhanced the conductivity. The contribution of graphenes coated onto the anode had a similar effect as that shown in Figure 4.

As shown in Figure 6, MFC-CCP and MFC-NCP with platinum and CNT on the carbon cloth cathode were different in the anodic treatment (with CNT or not). The maximum power density of MFC-NCP and MFC-CCP is $90.5 \mu \mathrm{W} \mathrm{m}{ }^{-2}$ and $378 \mu \mathrm{W} \mathrm{m}{ }^{-2}$, respectively. The power density obtained by MFC-CCP is about 4 times that obtained by MFC-NCP with the anode without CNT. The MFCs with graphene/CNT coated onto the electrode can significantly improve the power density. The anode modified by graphene or CNT was expected to provide E. coli with more space to attach and grow. From the results obtained by Zhu et al. [29], surface modifications of anode materials are important for enhancing power generation of microbial fuel cell.

As shown in Figure 7, the polarization curves all had the same trend. The MFC-NP maximum power density was $51 \mu \mathrm{W} \mathrm{m}^{-2}$ while that of MFC-NN was merely $2.25 \mu \mathrm{W} \mathrm{m}{ }^{-2}$, which showed that the two power densities differed by over 20 times. Furthermore, adding the cathode platinum catalyst can effectively enhance the performance. After coating the cathode with CNT and using a cathodic catalyst, the maximal power density is increased to $90.5 \mu \mathrm{W} \mathrm{m}^{-2}$ (MFC-NCP). If CNTs are replaced with a graphene as a coating material, the power density can be further increased to $159 \mu \mathrm{W} \mathrm{m}{ }^{-2}$ (MFC-NGP). The power density obtained by MFC-NGP is about 3.1 times more than that obtained by MFC-NP and that obtained by MFC-NCP is about 1.8 times more than that obtained by MFC-NP. The experimental results demonstrate that the kinetic rate of the reaction is changed by the catalyst in cathode. Moreover, adding CNTs or graphene on

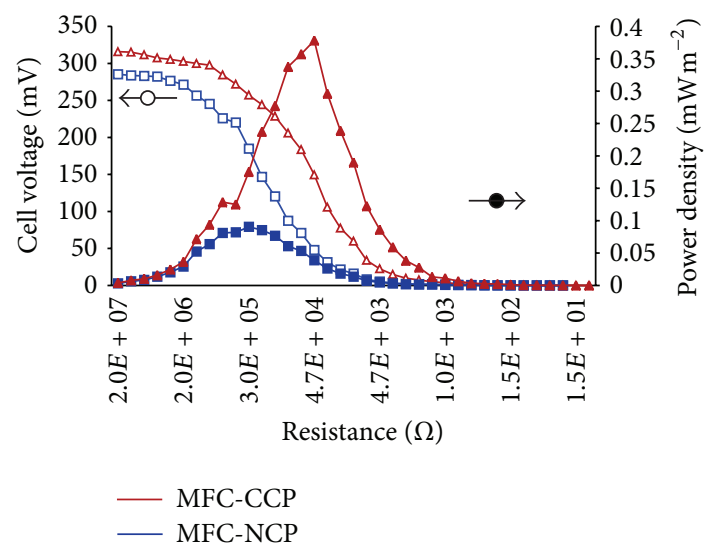

FIGURE 6: Performance diagram for the cases of the anode coated with CNTs or not and with platinum and CNTs coated on the cloth cathode.

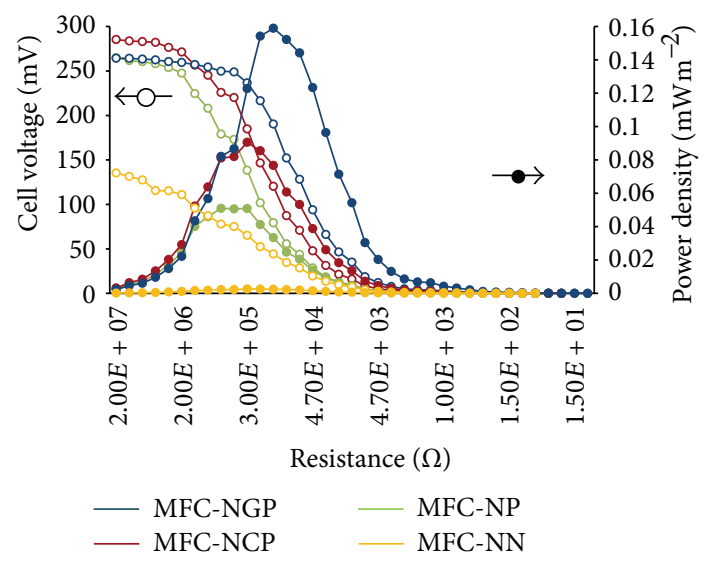

FIGURE 7: Performance diagram for the cases of the cathode coated with different materials and the plain cloth anode only.

the cathode can not only effectively enlarge the surface area but also enhance the reaction rate. The improvement in cathode catalyst performance was realized by coating of CNTs or graphene. Therefore, the improvement in the performance allows the reduction of expenditure on high cost Pt catalyst.

Among all the experimental results, graphene modified electrodes showed better performance on the power generation than CNT modified ones no matter whether graphene is on the anode or on the cathode. The possible reason was because that graphene had better electrical conductivity property and broader surface area than CNT. Since the length of $E$. coli is about $1 \mu \mathrm{m}$, the obtained three-dimensional structure stacked by random orientations of graphenes could result in more space for the microbe to adhere than that by CNTs. That is, surface roughness of the accumulated CNTs was relatively smaller than that of the accumulated graphenes for the dimensional level of $E$. coli.

3.3. Internal Resistance. Based on the experimental data, the internal resistance can be calculated by polarization slop method as the results shown in Table 2. 
TABLE 2: Internal resistances of MFCs for different experiments.

\begin{tabular}{lc}
\hline Experimental cases & $R_{\text {in }}(\mathrm{k} \Omega)$ \\
\hline MFC-NN & 377 \\
MFC-GN & 154 \\
MFC-CN & 215 \\
MFC-NP & 367 \\
MFC-GP & 17 \\
MFC-CP & 32 \\
MFC-NGP & 153 \\
MFC-GGP & 5.6 \\
MFC-NCP & 326 \\
MFC-CCP & 46 \\
\hline
\end{tabular}

For the anodic modification, the internal resistance was reduced from $377 \mathrm{k} \Omega$ for both the normal electrodes (MFC$\mathrm{NN})$ to $215 \mathrm{k} \Omega$ (MFC-CN) and $154 \mathrm{k} \Omega$ (MFC-GN) when the anode was modified by CNTs and graphene, respectively. Moreover, the internal resistance was significantly reduced from $367 \mathrm{k} \Omega$ for both normal electrodes with cathodic catalyst (MFC-NP) to $32 \mathrm{k} \Omega$ (MFC-CP) and $17 \mathrm{k} \Omega$ (MFC-GP) when the anode was modified by CNTs and graphene with cathodic catalyst, respectively.

For the cathodic modification, the internal resistance was slightly reduced from $367 \mathrm{k} \Omega$ (MFC-NP) to $326 \mathrm{k} \Omega$ for the case of cathode modified by CNTs (MFC-NCP) and largely decreased to $153 \mathrm{k} \Omega$ for the case of cathode modified by graphene (MFC-NGP). For the MFC systems with anode modified by graphene and cathodic catalyst, the internal resistance was reduced from $17 \mathrm{k} \Omega$ (MFC-GP) to about one-third $(5.6 \mathrm{k} \Omega$ ) while the cathode was further modified by graphene (MFC-GGP). In addition, MFC systems with the modified electrodes by graphene showed higher power density and lower internal resistance than those by CNTs for the same electrode conditions. Furthermore, the anodic modification by CNTs or graphene showed higher effect on the performance than the cathodic modification did.

Overall, the internal resistance was tremendously reduced from $377 \mathrm{k} \Omega$ (MFC-NN) to $5.6 \mathrm{k} \Omega$ (MFC-GGP). Compared to the similar electrode conditions except the modified carbon-based materials, the internal resistance was tremendously decreased from $367 \mathrm{k} \Omega$ (MFC-NP) to $5.6 \mathrm{k} \Omega$ (MFC-GGP). To sum up, the low internal resistance effect after the electrodes were modified by CNTs or graphene was the proof that CNT and graphene had such excellent electrical conductivity so as to improve the efficiency of electron transmission and hence higher power density.

\section{Conclusions}

Membrane free air-cathode microbial fuel cells (MFCs) were constructed using different types of composite electrodes, with or without $\mathrm{CNT}$ /graphene modified carbon cloth. From the experimental results of the MFC performance, the addition of CNT and graphene enhanced the power density and reduced the internal resistance. The electrodes modified by graphene showed better performance on the power density and lower internal resistance than those modified by CNTs did. The surface roughness of the accumulated CNTs was relatively smaller than that of the accumulated graphenes at the dimensional level of $E$. coli and the obtained threedimensional structure stacked by random orientations of graphenes could result in more space for the microbe to attach than that by CNTs since the length of $E$. coli was about $1 \mu \mathrm{m}$. The internal resistance was significantly reduced from $377 \mathrm{k} \Omega$ for the normal case (MFC-NN) to $5.6 \mathrm{k} \Omega$ for the case of both electrodes modified by graphene with cathodic catalyst (MFC-GGP). This was the proof that the improvement of power density and low internal resistance related to the larger surface area and higher conductivity of graphene or CNT. In addition, the MFC systems with the modified electrodes by graphene showed higher power density and lower internal resistance than those by CNTs for the same electrode conditions. Moreover, the anodic modification by carbon-based materials had higher improvement than the cathodic modification. As the modified electrode of aircathode MFC can significantly enhance the performance of power generation with tremendous cost saving, MFC has a tremendous potential for more extensive and practical applications in the near future.

\section{Conflict of Interests}

The authors declare that there is no conflict of interests regarding the publication of this paper.

\section{Acknowledgment}

The authors gratefully acknowledge discussions with Professor Hwan-You Chang from Department of Medical Science, National Tsing Hua University, and the microbe support.

\section{References}

[1] Z. W. Du, H. R. Li, and T. Y. Gu, "A state of the art review on microbial fuel cells: a promising technology for wastewater treatment and bioenergy," Biotechnology Advances, vol. 25, no. 5, pp. 464-482, 2007.

[2] R. A. Bullen, T. C. Arnot, J. B. Lakeman, and F. C. Walsh, "Biofuel cells and their development," Biosensors and Bioelectronics, vol. 21, no. 11, pp. 2015-2045, 2006.

[3] B. E. Logan, B. Hamelers, R. Rozendal et al., "Microbial fuel cells: methodology and technology," Environmental Science and Technology, vol. 40, no. 17, pp. 5181-5192, 2006.

[4] D. R. Bond and D. R. Lovley, "Electricity production by Geobacter sulfurreducens attached to electrodes," Applied and Environmental Microbiology, vol. 69, no. 3, pp. 1548-1555, 2003.

[5] H. P. Bennetto, J. L. Stirling, K. Tanaka, and C. A. Vega, "Anodic reactions in microbial fuel cells," Biotechnology and Bioengineering, vol. 25, no. 2, pp. 559-568, 1983.

[6] M. H. Osman, A. A. Shah, and F. C. Walsh, "Recent progress and continuing challenges in bio-fuel cells. Part I: enzymatic cells," Biosensors and Bioelectronics, vol. 26, no. 7, pp. 3087-3102, 2011.

[7] M. H. Osman, A. A. Shah, and F. C. Walsh, "Recent progress and continuing challenges in bio-fuel cells. Part II: microbial," Biosensors and Bioelectronics, vol. 26, no. 3, pp. 953-963, 2010. 
[8] S. Cheng and B. E. Logan, "Ammonia treatment of carbon cloth anodes to enhance power generation of microbial fuel cells," Electrochemistry Communications, vol. 9, no. 3, pp. 492-496, 2007.

[9] X. Wang, S. Cheng, Y. Feng, M. D. Merrill, T. Saito, and B. E. Logan, "Use of carbon mesh anodes and the effect of different pretreatment methods on power production in microbial fuel cells," Environmental Science and Technology, vol. 43, no. 17, pp. 6870-6874, 2009.

[10] S. Cheng, H. Liu, and B. E. Logan, "Power densities using different cathode catalysts (Pt and CoTMPP) and polymer binders (nafion and PTFE) in single chamber microbial fuel cells," Environmental Science and Technology, vol. 40, no. 1, pp. 364-369, 2006.

[11] B. Logan, S. Cheng, V. Watson, and G. Estadt, "Graphite fiber brush anodes for increased power production in air-cathode microbial fuel cells," Environmental Science and Technology, vol. 41, no. 9, pp. 3341-3346, 2007.

[12] H.-Y. Tsai, C.-C. Wu, C.-Y. Lee, and E. P. Shih, "Microbial fuel cell performance of multiwall carbon nanotubes on carbon cloth as electrodes," Journal of Power Sources, vol. 194, no. 1, pp. 199-205, 2009.

[13] S. Cheng, H. Liu, and B. E. Logan, "Increased performance of single-chamber microbial fuel cells using an improved cathode structure," Electrochemistry Communications, vol. 8, no. 3, pp. 489-494, 2006.

[14] H. Liu, S. Cheng, and B. E. Logan, "Power generation in fed-batch microbial fuel cells as a function of ionic strength, temperature, and reactor configuration," Environmental Science and Technology, vol. 39, no. 14, pp. 5488-5493, 2005.

[15] D. H. Park and J. G. Zeikus, "Improved fuel cell and electrode designs for producing electricity from microbial degradation," Biotechnology and Bioengineering, vol. 81, no. 3, pp. 348-355, 2003.

[16] H. Liu, R. Ramnarayanan, and B. E. Logan, "Production of electricity during wastewater treatment using a single chamber microbial fuel cell," Environmental Science and Technology, vol. 38, no. 7, pp. 2281-2285, 2004.

[17] H. Liu and B. E. Logan, "Electricity generation using an aircathode single chamber microbial fuel cell in the presence and absence of a proton exchange membrane," Environmental Science and Technology, vol. 38, no. 14, pp. 4040-4046, 2004.

[18] B. Cercado-Quezada, M.-L. Delia, and A. Bergel, "Treatment of dairy wastes with a microbial anode formed from garden compost," Journal of Applied Electrochemistry, vol. 40, no. 2, pp. 225-232, 2010.

[19] J. Menicucci, H. Beyenal, E. Marsili, R. A. Veluchamy, G. Demir, and Z. Lewandowski, "Procedure for determining maximum sustainable power generated by microbial fuel cells," Environmental Science and Technology, vol. 40, no. 3, pp. 1062-1068, 2006.

[20] B. E. Logan, C. Murano, K. Scott, N. D. Gray, and I. M. Head, "Electricity generation from cysteine in a microbial fuel cell," Water Research, vol. 39, no. 5, pp. 942-952, 2005.

[21] S. Cheng, H. Liu, and B. E. Logan, "Increased power generation in a continuous flow MFC with advective flow through the porous anode and reduced electrode spacing," Environmental Science and Technology, vol. 40, no. 7, pp. 2426-2432, 2006.

[22] T. Sharma, A. L. M. Reddy, T. S. Chandra, and S. Ramaprabhu, "Development of carbon nanotubes and nanofluids based microbial fuel cell," International Journal of Hydrogen Energy, vol. 33, no. 22, pp. 6749-6754, 2008.
[23] C.-T. Wang, Y.-M. Chen, Z.-Q. Qi, and Y.-C. Yang, "Carbon nanotube planted on Ni-based alloy in microbial fuel cell," Journal of Nanomaterials, vol. 2013, Article ID 435960, 5 pages, 2013.

[24] C. Lee, X. Wei, J. W. Kysar, and J. Hone, "Measurement of the elastic properties and intrinsic strength of monolayer graphene," Science, vol. 321, no. 5887, pp. 385-388, 2008.

[25] H. Choi, H. Kim, S. Hwang, W. Choi, and M. Jeon, "Dyesensitized solar cells using graphene-based carbon nano composite as counter electrode," Solar Energy Materials and Solar Cells, vol. 95, no. 1, pp. 296-300, 2011.

[26] C.-H. Hsu, C.-C. Lai, L.-C. Chen, and P.-S. Chan, "Enhanced performance of dye-sensitized solar cells with graphene/ $\mathrm{ZnO}$ nanoparticles bilayer structure," Journal of Nanomaterials, vol. 2014, Article ID 748319, 6 pages, 2014.

[27] J. R. Miller, R. A. Outlaw, and B. C. Holloway, "Graphene electric double layer capacitor with ultra-high-power performance," Electrochimica Acta, vol. 56, no. 28, pp. 10443-10449, 2011.

[28] A. J. Bard and L. R. Faulkner, Electrochemical Methods: Fundamentals and Applications, John Wiley \& Sons, Hoboken, NJ, USA, 2nd edition, 2001.

[29] N. Zhu, X. Chen, T. Zhang, P. Wu, P. Li, and J. Wu, "Improved performance of membrane free single-chamber air-cathode microbial fuel cells with nitric acid and ethylenediamine surface modified activated carbon fiber felt anodes," Bioresource Technology, vol. 102, no. 1, pp. 422-426, 2011. 

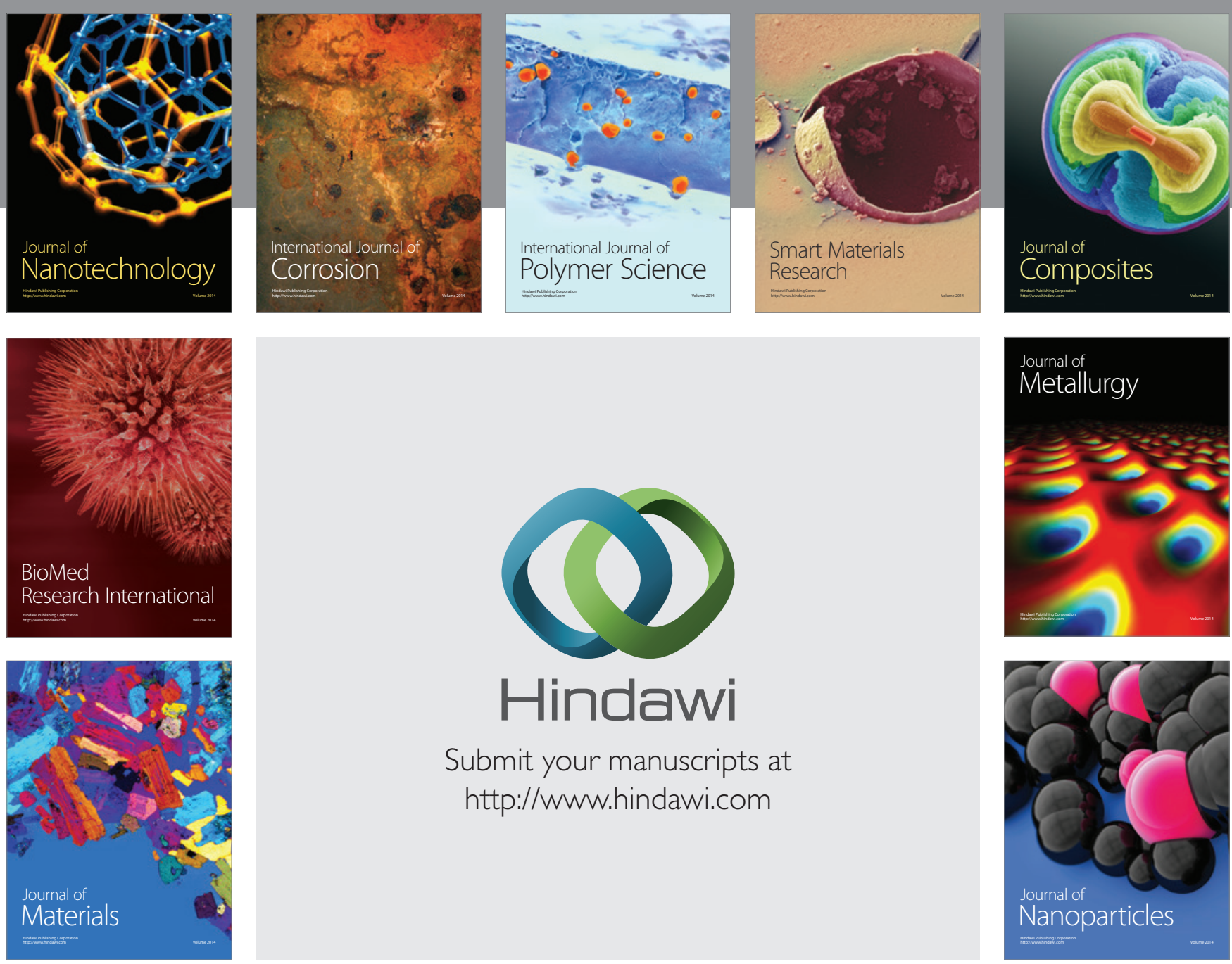

Submit your manuscripts at http://www.hindawi.com
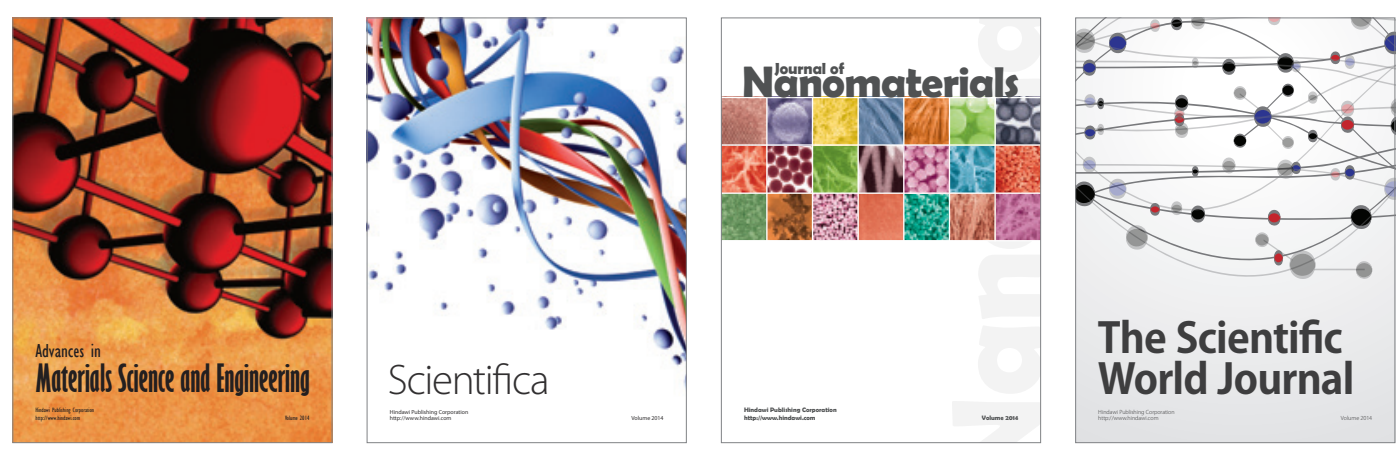

\section{The Scientific World Journal}
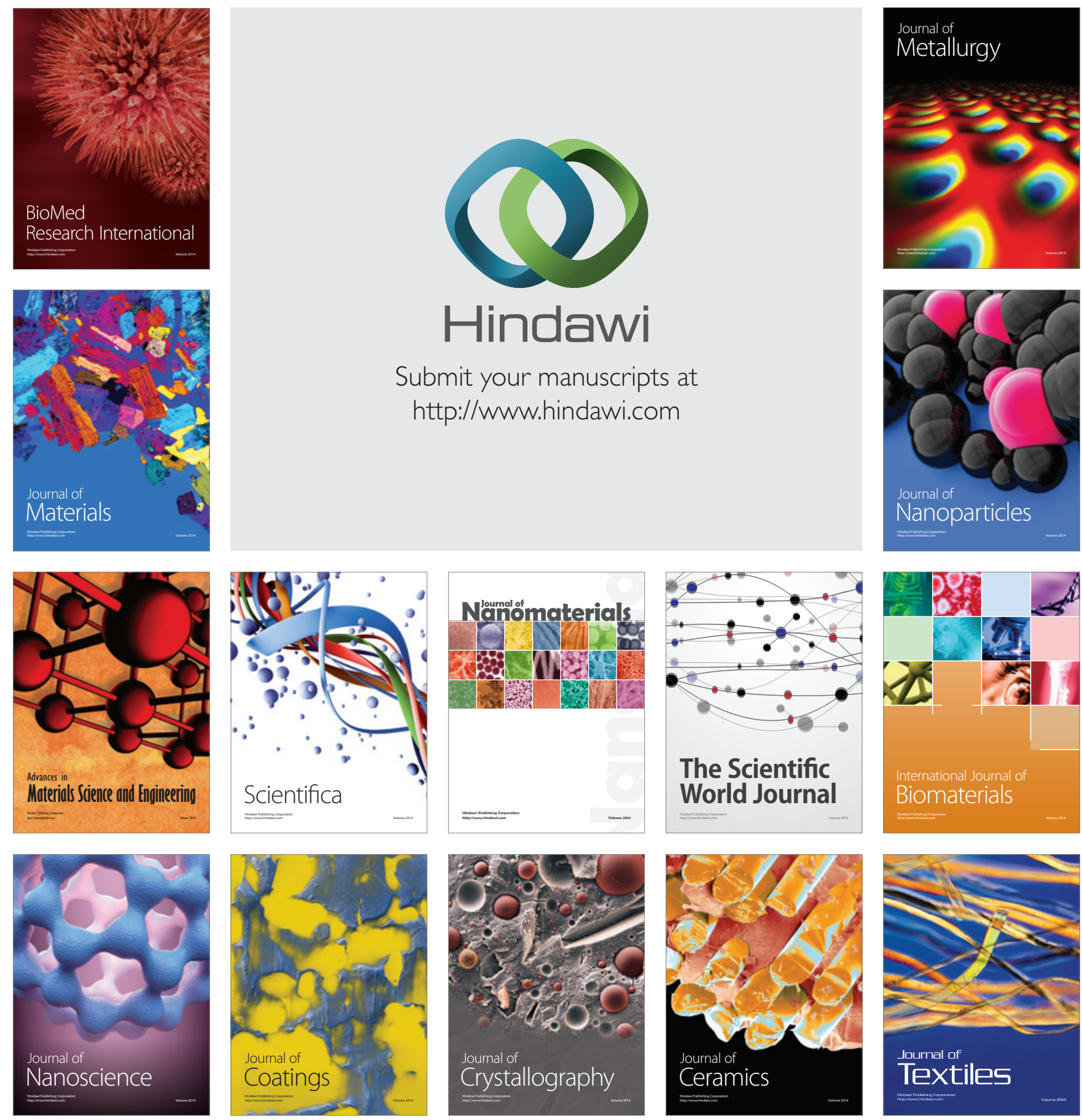